\title{
ALCACHOFRA: NOVA PLANTA HOSPEDEIRA DE Pratylenchus penetrans NO ESTADO DE SÃO PAULO, BRASIL
}

\section{ARTICHOKE: Pratylenchus penetrans NEW HOST PLANT IN BRAZIL}

\author{
Carlos Eduardo Rossi $^{1} \quad$ Ailton Rocha Monteiro ${ }^{2}$
}

\section{RESUMO}

\begin{abstract}
Relata-se a ocorrência do nematóide das lesões radiculares, Pratylenchus penetrans em alcachofra no Estado de São Paulo, Brasil. A estimativa da densidade populacional foi 224 espécimes no solo $\left(250 \mathrm{~cm}^{3}\right)$ e 720 nas raízes (10g). As plantas atacadas mostravam-se com crescimento reduzido.
\end{abstract}

Palavras-chave: Cynara scolymus, ocorrência, nematóide.

\section{SUMMARY}

It is reported the occurrence of lesion nematode, Pratylenchus penetrans on artichoke in the State of São Paulo, Brazil. The population density estimated was 224 specimens in the soil $\left(250 \mathrm{~cm}^{3}\right)$ and 720 in the roots $(10 \mathrm{~g})$. Attacked plants showed growth reduction.

Key words: Cynara scolymus, occurrence, plant-parasitic nematode.

A alcachofra (Cynara scolymus L. família Asteraceae) é hortaliça perene, cujo cultivo realizase em locais de clima ameno. A multiplicação da planta é assexuada e se faz por meio de rebentões (CAMARGO, 1984). As principais espécies de nematóides que a parasitam são as das galhas, Meloidogyne arenaria (Neal) Chitwood, $\boldsymbol{M}$. incognita (Kofoid \& White) Chitwood e $\boldsymbol{M}$. javanica (Treub) Chitwood, e o reniforme Rotylenchulus reniformis Linford \& Oliveira
(GOODEY et al., 1965). No Brasil, CARNEIRO (1992) cita M. arenaria e M. javanica que, segundo o autor danificam e comprometem totalmente a produção de três cultivares dessa asterácea no Rio Grande do Sul. Amostras de solo e de raízes foram coletadas em lavoura de alcachofra 'Roxa-de-SãoRoque', situada no município paulista de Campos do Jordão (1630m de altitude), para análise nematológica. Nessa lavoura o produtor havia observado, nos dois últimos anos, queda de produção, apesar de as plantas não apresentarem outros sintomas.

A extração dos nematóides do solo $\left(250 \mathrm{~cm}^{3}\right)$ foi feita pelo método de JENKINS (1964) e os das raízes (10g) pelo de COOLEN \& D'HERDE (1972) sendo, posteriormente, fixados em formalina $4 \%$.

Verificou-se a ocorrência de Pratylenchus penetrans (Cobb) Sher \& Allen estimado em 224 exemplares na alíquota do solo $\left(250 \mathrm{~cm}^{3}\right)$ e 720 na das raízes (10g), e Helicotylenchus dihystera (Cobb) Sher calculado em 480 no solo $\left(250 \mathrm{~cm}^{3}\right)$ e 360 nas raízes $(10 \mathrm{~g})$. O parasitismo por esses nematóides, especialmente por $\boldsymbol{P}$. penetrans, pode ser a causa da queda de produção. A ausência de outros sintomas da nematose talvez se deva ao alto índice $(3,9 \%)$ de matéria orgânica do solo, que atenua ou mascara os danos.

\footnotetext{
${ }^{1}$ Engenheiro Agrônomo, Mestre em Ciências, Pesquisador Científico II, Centro Experimental do Instituto Biológico, C.P. 70, 13001-970, Campinas, SP. E-mail: crossi@biologico.br. Autor para correspondência.

${ }^{2}$ Engenheiro Agrônomo, Doutor em Ciências, Professor Titular Aposentado, Departamento de Entomologia, Fitopatologia e Zoologia Agrícola, ESALQ/USP, C.P. 09, 13418-900, Piracicaba, SP. E-mail: armontei@ carpa.ciagri.usp.br. 
No Brasil, esse importante nematóide das lesões já havia sido relatado em laranja e cravo (RAHM, 1928; RAHM, 1929), identificação posta em dúvida por LOOF (1960) e não considerada em trabalhos subseqüentes de sua ocorrência no Brasil. Também foi relatado em alho, em Minas Gerais e no Rio Grande do Sul (CHARCHAR et al., 1980), mandioquinha-salsa em São Paulo (MONTEIRO, 1980), crisântemo em São Paulo (FERRAZ \& MONTEIRO, 1983; SILVEIRA $\boldsymbol{e t}$ al., 1988), capim-colchão, Digitaria sanguinalis e ervilha em São Paulo (FERRAZ \& MONTEIRO, 1983), soja no Rio Grande do Sul (MONTEIRO \& COVOLO, 1985) e em uma amostra de pinheiro importada da Alemanha (SILVEIRA et al., 1986).

Como essa planta normalmente se multiplica por rebentões, recomenda-se uma análise prévia das matrizes antes do plantio para se evitar a disseminação do parasito para novas áreas de cultivo. Estudos a respeito da distribuição na área e da patogenicidade do parasito à alcachofra estão sendo realizados. Recomenda-se, ainda, como medidas de controle, a rotação de culturas com Tagetes e a incorporação de compostos orgânicos, tais como cama de frango ou torta de mamona, que ocasionam uma diminuição do nível populacional do nematóide no solo (CORBETT, 1973).

\section{REFERÊNCIAS BIBLIOGRÁFICAS}

CAMARGO, L.S. As hortaliças e seu cultivo. Campinas : Fundação Cargill, 1984. 448p.

CARNEIRO, R.M.D.G. Ocorrência de Meloidogyne javanica e M. arenaria em três cultivares de alcachofra (Cynara scolymus). Nematologia Brasileira, v.16, n.1/2, p.89, 1992.

CHARCHAR, J.M., HUANG, C.S., MENEZES SOBRINHO, J.A., et al. Nematóides fitoparasitos associados a plantas de alho (Allium sativum L. e Allium ampeloprasum L.) coletadas nos principais Estados produtores do Brasil. Fitopatologia Brasileira, v.5, n.1, p.105-114, 1980.

COOLEN, W.A., D'HERDE, C.J. A method for the quantitative extraction of nematodes from plant tissue. Ghent : State Agriculture Research Center, 1972. 77p.

CORBETT, D.C.M. Pratylenchus penetrans. St. Albans: Commonwealth Institute Helminthology, 1973. 4p. (C.I.H. Descriptions of plant-parasitic nematodes, 25).

FERRAZ, L.C.C.B., MONTEIRO, A.R. Nova ocorrência de Pratylenchus penetrans no Brasil. Revista de Agricultura, v.58, n.4, p.301-303, 1983.

GOODEY, J.B., FRANKLIN, M.T., HOOPER, D.J. T. Goodey's the nematode parasites of plants catalogued under their hosts. Farnham Royal, England : Commonwealth Agricultural Bureaux, 1965. 214p.

JENKINS, W.R. A rapid centrifugal-flotation technique for separating nematodes from soil. Plant Disease Reporter, v.48, p.629, 1964.

LOOF, P.A.A. Taxonomic studies on the genus Pratylenchus (Nematoda). Tijdschrift over Plantenziekten, v.66, p.2990,1960 .

MONTEIRO, A.R., COVOLO, G. Pratylenchus penetrans parasita soja, Glycine max, no Brasil. Nematologia Brasileira, v.9, p.14, 1985

MONTEIRO, A.R. O nematóide Pratylenchus penetrans causa necrose em mandioquinha salsa no Brasil. Reunião Brasileira de Nematologia, v.4, p.59, 1980.

RAHM, G. Alguns nematodes parasitas e semi-parasitas das plantas culturaes do Brasil. Archivos do Instituto Biologico de Defesa Agricola e Animal, v.1, p.239-252, 1928.

RAHM, G. Nematodes parasitas e semi-parasitas de diversas plantas culturaes do Brasil. Archivos do Instituto Biologico de Defesa Agricola e Animal, v.2, p.67-136, 1929.

SILVEIRA, S.G.P., CURI, S.M., TOLEDO, A.C.D. Ocorrência do nematóide Pratylenchus penetrans em solo de crisântemo no Estado de São Paulo. Fitopatologia Brasileira, v.13, n.1, p.71-72, 1988.

Ciência Rural, v. 31, n. 4, 2001. 